\title{
MALIGNANT SOLITARY FIBROUS TUMOUR OF THE EXTREMITIES
}

\author{
Daniel Chang $^{1}$, Cláudia Regina Gomes Cardim Mendes de Oliveira ${ }^{2}$, Carlos Fernando Saito ${ }^{2}$
}

\section{ABSTRACT}

Extrapleural solitary fibrous tumor (SFT) is a rare mesenchymal neoplasm, with less than 40 cases reported affecting the extremities so far. This tumor affects preferentially middle-aged patients (median: 50 years) and shows no predilection for sex. We report a case with typical clinical, radiologic, histopathologic and immunohistochemical features, discussing the importance of differential diagnosis of other sarcomas. Little is known about the biological behavior of SFT. Risk factors for shorter metastasis-free survival include impaired surgical margins, tumor size greater than $10 \mathrm{~cm}$ and malignant histology. Complete excision is the recommended treatment.

Keywords: Hemangiopericytoma. Tumor

Citation: Chang D, Oliveira CRG, Saito CF. Malignant solitary fibrous tumour of the extremities. Acta Ortop Bras. [online]. 2010; 18(2):107-9. Available from URL: http:// www.scielo.br/aob

\section{INTRODUCTION}

Extrapleural solitary fibrous tumor (SFT) is a mesenchymal tumor of probable fibroblastic type with presence of vessels exhibiting a branching pattern that resembles that of hemangiopericytoma. ${ }^{1,2}$ Extrapleural solitary fibrous tumors, many of which were called hemangiopericytomas in the past, are morphologically similar to solitary fibrous tumors of the pleura.

They occur in adults in a broad age bracket from 20 to 70 years, more frequently around 54 years, without gender predilection. ${ }^{1,3} \mathrm{As}$ far as location is concerned, $40 \%$ appear in subcutaneous tissue, but also occur in deep soft tissues of the extremities, head and neck (mainly orbit), thoracic wall, mediastine, pericardium, retroperitoneum and abdominal cavity. They can also appear in rarer places such as the meninges, salivary glands, lungs, liver, gastrointestinal tract, adrenal glands, bladder, prostate and testicles. ${ }^{3-5}$ In $5 \%$ of cases they are the origin of paraneoplastic syndromes related to hypoglycemia resulting from the production of insulin-like factors. ${ }^{4}$ So far there are fewer than 40 cases described in literature in soft parts of extremities. ${ }^{1,3}$ The vast majority are benign and cured by simple complete excision of the lesion. In 10 to $30 \%$ of cases, however, they have aggressive biological behavior with recurrences, metastases or both. ${ }^{6,7}$

With the use of imaging exam, computed tomography or magnetic nuclear resonance, SFT represents a circumscribed lesion, sometimes infiltrative, with solid and cystic areas, and possible calcifications. $^{8}$
We report a case with the characteristic clinical, radiological, histological and immunohistochemical aspects, discussing the malignancy criteria, differential diagnoses and treatment, in light of a review of the pertinent literature.

\section{MATERIAL AND METHOD}

Female patient aged 53 years, with clinical picture of progressive increase of volume and pain in the right thigh region seven months ago, without other constitutional symptoms. Imaging exams (computed tomography and magnetic nuclear resonance) were followed by surgical resection of the lesion. The material was analyzed macroscopically and representative samples were submitted to routine histological processing for paraffin embedding and hematoxylin and eosin (H\&E) stain for microscopic evaluation. Moreover, immunohistochemical reactions for the following markers: CD34 (clone QBEnd/10 - Biogenex ${ }^{\circledR}$, Denmark; dilution 1:500) CD99 (clone 12E7 - Dakocytomation ${ }^{\circledast}$, USA; dilution 1:800), Bcl-2 (clone 124 - Dakocytomation ${ }^{\circledR}$, USA; dilution 1:1000), Vimentina (clone V9 - Dakocytomation ${ }^{\circledR}$, USA; dilution 1:800), EMA (clone E29 - Dakocytomation ${ }^{\circledR}$, USA; dilution 1:200) and Ki-67 (clone MIB-1 Dakocytomation $^{\circledR}$, USA; dilution 1:200), were also performed.

\section{RESULTS}

In the imaging, computed tomography and magnetic nuclear resonance exams, expansive and infiltrative lesion was identified in subcutaneous tissue and muscular plane with solid and cystic components. (Figure 1)

All the authors declare that there is no potential conflict of interest referring to this article.

1 - Fleury Medicina e Saúde

2 - LIM 41 - Laboratory for Medical Investigation of the Musculoskeletal System of the Department of Orthopedics and Traumatology HC/FMUSP

Mailing Address: Fleury Medicina e Saúde. Av. Gal. Waldomiro de Lima, 508. Jabaquara - 04344-070 São Paulo-SP. Brazil. e-mail: daniel.chang@fleury.com.br

Article received on $01 / 24 / 08$ and approved on $05 / 23 / 08$

Acta Ortop Bras. 2010; 18(2):107-9 


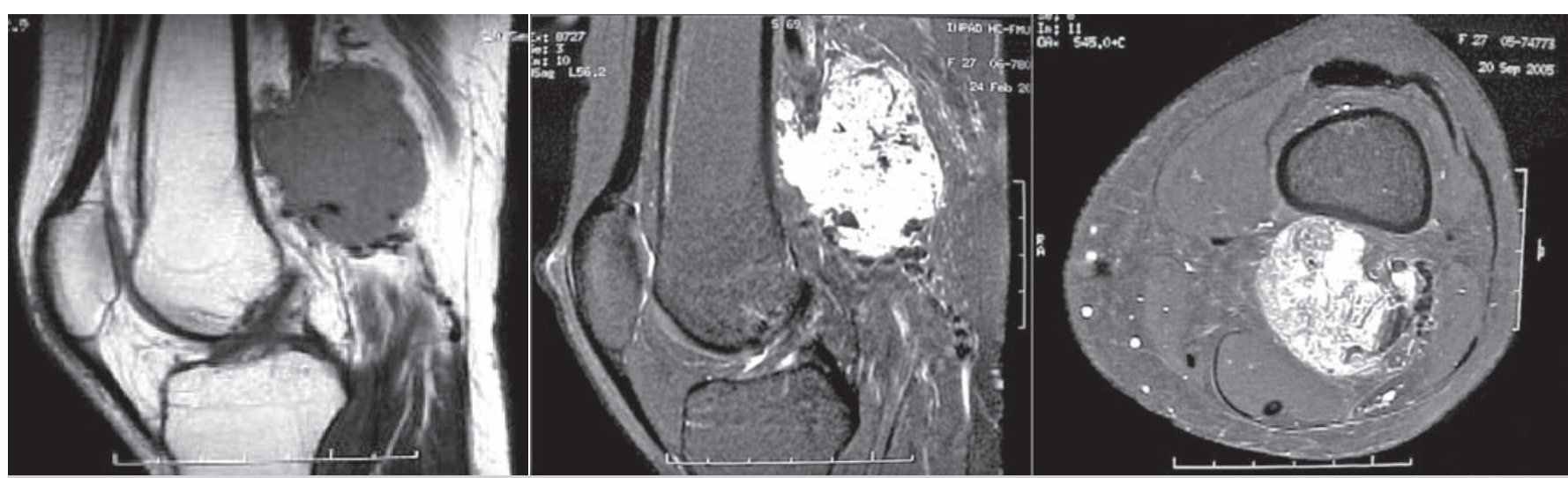

Figure 1 - Radiological imaging exams with expansive and infiltrative lesion in subcutaneous tissue and muscular plane with solid and cystic components.

The macroscopic analysis evidenced nodular lesion, measuring 4.0 $\mathrm{cm}$ in diameter, of firm consistency, light brown, with softened and cystic permeable areas, besides infiltrative edges in focal areas. (Figure 2)

The histopathologic study of the lesion showed proliferation of cells, mostly spindle shaped, with focal areas comprised of rounded cells, with atypias, besides vascular component of permeated hemangiopericytoma pattern (pattern of thin vessels in a stag horn branching pattern), focal points of necrosis and mitoses, including atypical ones, with count of 5 mitoses per 10 fields of high amplification (400x). (Figure 3)

The immunohistochemical reactions revealed positivity for the following markers: CD34, CD99, Bcl-2, Vimentine and Ki-67 in 15\% of the neoplastic cells. EMA was negative. (Figure 4)

Hence the conclusion reached with the data presented was a diagnosis of solitary fibrous tumor of aggressive biological behavior (malignant variant).

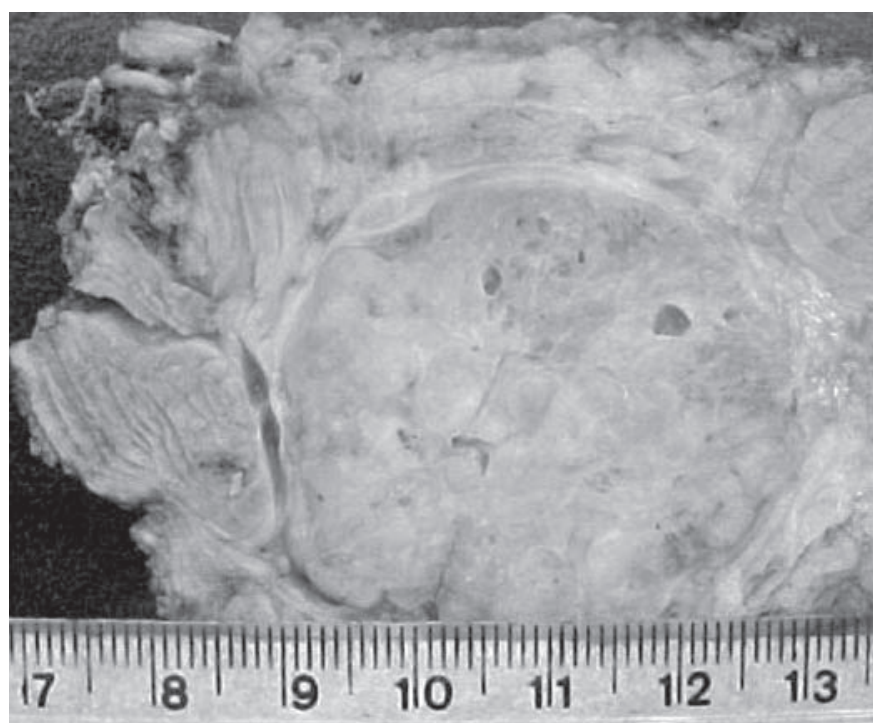

Figure 2 - Macroscopy - nodular lesion of firm consistency, light brown, with softened and cystic permeated areas.

\section{DISCUSSION}

Solitary fibrous tumor (SFT) is a mesenchymal neoplasia of uncertain histogenesis, yet of probable fibroblastic type. The ultrastructural characteristics are nonspecific with the tumor cells frequently presenting fibroblastic or myofibroblastic phenotype and/ or with pericitic differentiation. Moreover, SFT is heterogeneous from the cytogenetic point of view and has variable degrees of biological behavior. ${ }^{2}$

So far there are fewer than 40 cases described in literature in soft parts of extremities. ${ }^{1,3}$ The vast majority are benign and cured by simple complete excision of the lesion. In 10 to $30 \%$ of the cases, however, they have aggressive biological behavior with recurrences, metastases or both. ${ }^{6,7}$

The distinction between benign and malignant STF is frequently difficult and divergent in the current literature. Some authors consider the infiltrative nature the most important criterion for malignancy diagnosis. ${ }^{9,10}$ Other authors define that cytological atypias, pres-

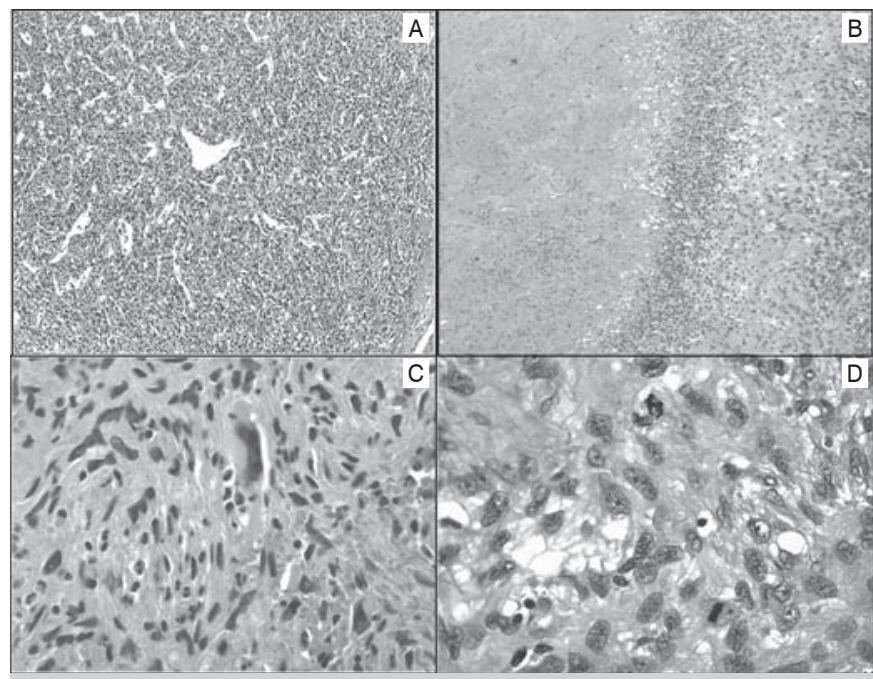

Figure $3-$ A) Proliferation of spindle-shaped cells with vascular component of permeated hemangiopericytoma pattern (H\&E 100x), B) Tumor necrosis area on the left (H\&E 200x), C) Proliferation of cells, most of which are spindle shaped with presence of atypias (H\&E 400x) and D) Presence of mitoses, including atypical ones (H\&E 500x). 


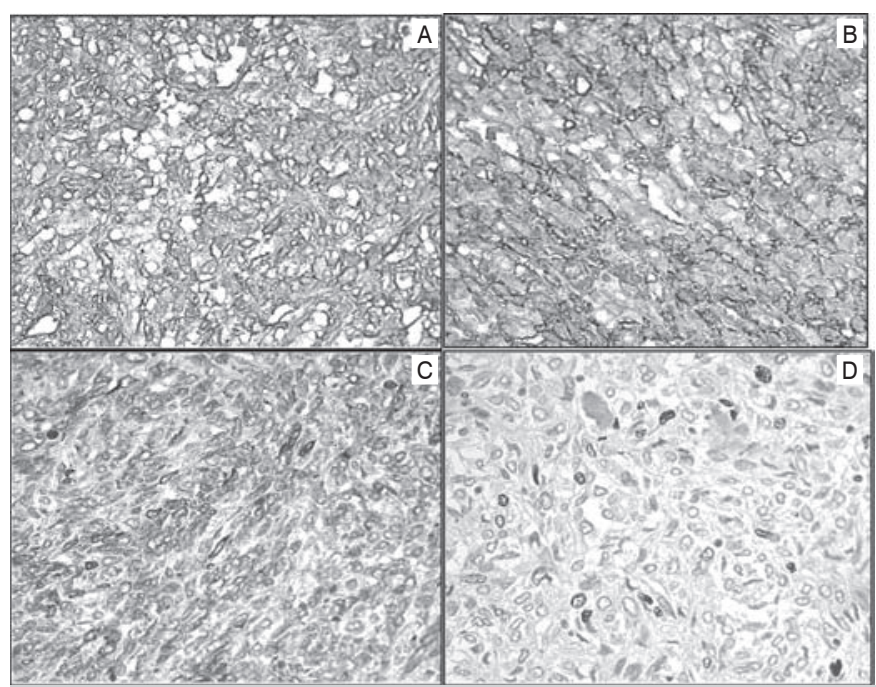

Figure 4 - A) Immunohistochemical panel: positivity for CD34 (200x), B) Immunohistochemical panel: positivity for CD99 (200x), C) Immunohistochemical panel: positivity for Bcl-2 (200x) and D) Immunohistochemical panel: positivity for Ki-67 (400x).

ence of necrosis and the limit above 4 mitoses per 10 fields of high amplification are criteria of malignant behavior, particularly in those located in extremities, ${ }^{3}$ which we observed in the present case reported.

Moreover, some authors have considered that Ki-67 from 6.1\% up could be one of the criteria for evaluation of prognosis and aggressive behavior. ${ }^{9-11}$ In the reported case there was a Ki-67 of 15\% verified, which is compatible with aggressive behavior.

The differential diagnosis includes benign and malignant lesions such as: fibromatosis, fibrosarcoma, malignant peripheral nerve sheath tumor, malignant fibrous histiocytoma and dermatofibrosarcoma protuberans. , $^{3,7,12}$
Besides the histological findings, the immunohistochemical exam is essential for precise diagnosis, whereas in SFT there is positivity for CD34 (90-95\% of the cases), CD99 (70\% of the cases) and Bcl-2 (50\% of the cases). ${ }^{2}$

Among the differential diagnoses propounded, synovial sarcoma is also positive for the markers CD99 and Bcl-2; hence it is necessary to perform the immunohistochemical reaction for EMA, which is positive in synovial sarcoma and negative in SFT, thus allowing the distinction between these entities, as performed in this case, which presented fusocellular aspect similar to of synovial sarcoma.

As regards treatment, there are some relevant points in SFT that should be analyzed, such as: extent of resection is the main prognosis factor, whereas invasion or metastasis can occur in tumors with benign aspect with incomplete resection; extrathoracic location increases the risk of recurrence ${ }^{7}$; impaired surgical margins and presence of histology with malignancy characteristics are recurrence factors; and, finally, impaired margins, tumor larger than $10 \mathrm{~cm}$ and malignant histological component are related to shorter metastases-free survival time..$^{8,10}$

Accordingly, in this case, the lesion was excised with free surgical margins and did not present relapse and/or metastasis in a followup period of one year and a half. However, relapses and metastases have a very late onset (up to 30 years after the first surgery), for which reason the clinical follow-up of these patients should be maintained indefinitely. ${ }^{6,13}$

\section{CONCLUSION}

The extrapleural solitary fibrous tumor is a rare mesenchymal neoplasia with fewer than 40 cases described in literature, located at the extremities. It preferentially affects patients in the fifth decade and has no gender predilection. The vast majority are benign and cured by complete excision of the lesion. However, 10 to $30 \%$ of cases have aggressive biological behavior with recurrences and/ or late-onset metastases, for which reason the clinical follow-up of these patients should be maintained indefinitely.

\section{REFERENCES}

1. Akisue T, Matsumoto K, Kizaki T, Fujita I, Yamamoto T, Yoshiya S et al. Solitary fibrous tumor in the extremity: case report and review of the literature. Clin Orthop Relat Res. 2003;(411):236-44.

2. Cafiero F, Gipponi M, Peressini A, Barabino P, Queirolo P, Nicolo M et al. Solitary fibrous tumor of the inguinal region: a clinicopathological, light-microscopic, immunohistochemical, electron microscopic and flow-cytometric DNA study. Anticancer Res. 2001;21:4091-4.

3. Anders JO, Arich M, Lan T, Wagner A. Solitary fibrous tumor in the thigh: review of the literature. J Cancer Res Clin Oncol. 2006;132:69-75.

4. Kuo W, Sirois D, Pemble C. Locally aggressive solitary fibrous tumor in the infraorbital region: a case report and review of the literature. Oral Surg Oral Med Oral Pathol Oral Radiol Endod. 2001;92:308-11.

5. Ogawa K, Tada T, Takahashi S, Sugiyama N, Inaguma S, Tahashi S et al. Malignant solitary fibrous tumor of the meninges. Virchows Arch. 2004; 444:459-64.

6. Gold J, Antonescu C, Hajdu C, Ferrone C, Hussain M, Lewis J et al. Clinicopathologic correlates of solitary fibrous tumors. Cancer. 2002;94:1057-68.

7. Hasegawa T, Matsuno Y, Shimoda T, Hasegawa F, Sano T, Hirohashi S. Ex- trathoracic solitary fibrous tumors: their histological variability and potentially aggressive behavior. Hum Pathol. 1999;30:1464-73.

8. Rakheja D, Wilson K, Meehan J, Schultz R, Maale G, Timmons C. Extrapleural benign solitary fibrous tumor in the shoulder of a 9-year-old girl: case report and review of the literature. Pediatr Dev Pathol. 2004;7:653-60.

9. Sun Y, Naito Z, Ishiwata T, Maeda S, Sugisakiu Y, Asano G. Basic FGF and Ki-67 protein useful for immunohistological diagnostic evaluations in malignant solitary fibrous tumor. Pathol Int. 2003;53:284-90.

10. Vallat-Decouvelaere AV, Dry SM, Fletcher CD. Atypical and malignant solitary fibrous tumors in extrathoracic locations: evidence of their comparability to intra-thoracic tumors. Am J Surg Pathol. 1998;22:1501-11.

11. Yoshimasu T, Oura S, Hirai I, Kokawa Y, Nishida M, Sasaki R et al. Histoculture drug response assay for solitary fibrous tumor-a-case report. Gan To Kagaku Ryoho. 2004;31:1547-9.

12. Clayton A, Salomao D, Keeney G, Nascimento A. Solitary fibrous tumor: a study of cytologic features of six cases diagnosed by fine-needle aspiration. Diagn Cytopathol. 2001;25:172-6.

13. Fukunaga M, Naganuma H, Nikaido T, Harada T, Ushigome S. Extrapleural solitary fibrous tumor: a report of seven cases. Modern Pathol. 1997;10:443-50. 